\title{
Association of Breast Cancer Irradiation With Cardiac Toxic Effects A Narrative Review
}

Icro Meattini, MD; Philip M. Poortmans, MD, PhD; Marianne Camille Aznar, PhD; Carlotta Becherini, MD; Elisabetta Bonzano, MD; Daniela Cardinale, MD, PhD; Daniel J. Lenihan, MD; Livia Marrazzo, MSc; Giuseppe Curigliano, MD, PhD; Lorenzo Livi, MD

IMPORTANCE To promptly recognize and manage cardiovascular (CV) risk factors before, during, and after cancer treatment, decreasing the risk of cancer therapy-related cardiac dysfunction is crucial. After recent advances in breast cancer treatment, mortality rates from cancer have decreased, and the prevalence of survivors with a potentially higher CV disease risk has increased. Cardiovascular risks might be associated with the multimodal approach, including systemic therapies and breast radiotherapy (RT).

OBSERVATIONS The heart disease risk seems to be higher in patients with tumors in the left breast, when other classic CV risk factors are present, and when adjunctive anthracycline-based chemotherapy is administered, suggesting a synergistic association. Respiratory control as well as modern RT techniques and their possible further refinement may decrease the prevalence and severity of radiation-induced heart disease. Several pharmacological cardioprevention strategies for decreasing cardiac toxic effects have been identified in several guidelines. However, further research is needed to ascertain the feasibility of these strategies in routine practice.

CONCLUSIONS AND RELEVANCE This review found that evidence-based recommendations are lacking on the modalities for and intensity of heart disease screening, surveillance of patients after RT, and treatment of these patients. A multidisciplinary and multimodal approach is crucial to guide optimal management.

JAMA Oncol. doi:10.1001/jamaoncol.2020.7468

Published online March 4, 2021.

I dentification of patients with cancer who have an increased risk of death from heart disease is especially important given the advent of improved cancer therapy and the increasing age of the surviving population. ${ }^{1}$ Among patients with cancer in the US, the estimated heart disease-specific mortality rate is 10.61 per 10000 person-years, which is 2.24 times higher than the standardized rate for fatal heart disease. ${ }^{2}$ In 2017, coronary heart disease was the leading cause of deaths attributable to cardiovascular (CV) disease (42.6\%) in the US, followed by stroke (17.0\%), high blood pressure (10.5\%), heart failure (9.4\%), diseases of the arteries (2.9\%), and other conditions (17.6\%). ${ }^{3}$

Patients with prostate, colorectal, breast, or lung cancer constitute most of the patients with cancer dying of CV disease. ${ }^{2}$ Much of the CV risk is associated with age, obesity, diet, and a sedentary lifestyle, all of which have a predisposition to both cancer and CV disease. Therefore, it is crucial for health care professionals to promptly recognize and manage $\mathrm{CV}$ risk factors before, during, and after cancer treatment to lower the risk of cancer therapy-related cardiac dysfunction. This necessity has led to the development of the field of cardio-oncology, which refers to the treatment of CV disease in patients with cancer that focuses on the adverse effects of cancer therapy. ${ }^{4}$ After recent advances in breast cancer treatment, mortality rates from breast cancer have decreased. This decrease has led to a growing number of survivors with a potentially higher CV disease risk that might be associated with the multimodal ap- proach, including anthracycline-based chemotherapy, ${ }^{5}$ ERBB2 (formerly HER2) antagonists, ${ }^{6}$ and breast irradiation. ${ }^{7}$

Radiotherapy (RT) for early-stage breast cancer decreases recurrence rates and improves breast cancer-specific survival for most patients. ${ }^{8,9}$ Although radiation treatments for breast cancer have been optimized over time, long-term follow-up of some trials has shown that patients may havean increased risk of heart disease. This finding is most likely attributable to an incidental irradiation outside of the target volumes. ${ }^{10}$ Women who underwent radiotherapy for cancer of the left breast had higher rates of major cardiac toxic effects than those who underwent radiotherapy for cancer of the right breast, with a relative increase in the rate of major coronary events of $7.4 \%$ per Gy of radiation received by the heart and with no apparent threshold. ${ }^{11}$

This narrative review focuses on the pathophysiological mechanisms, clinical presentation, assessment and diagnosis, and toxic effect predictive models of radiation-induced heart disease (RIHD) as well as the strategies for treatment and prevention of morbidity and mortality in long-term heart disease.

\section{Observations}

\section{Pathophysiological Mechanisms}

Radiation-induced heart disease can occur as acute radiation myocarditis, although it mostly develops as a long-term consequence 


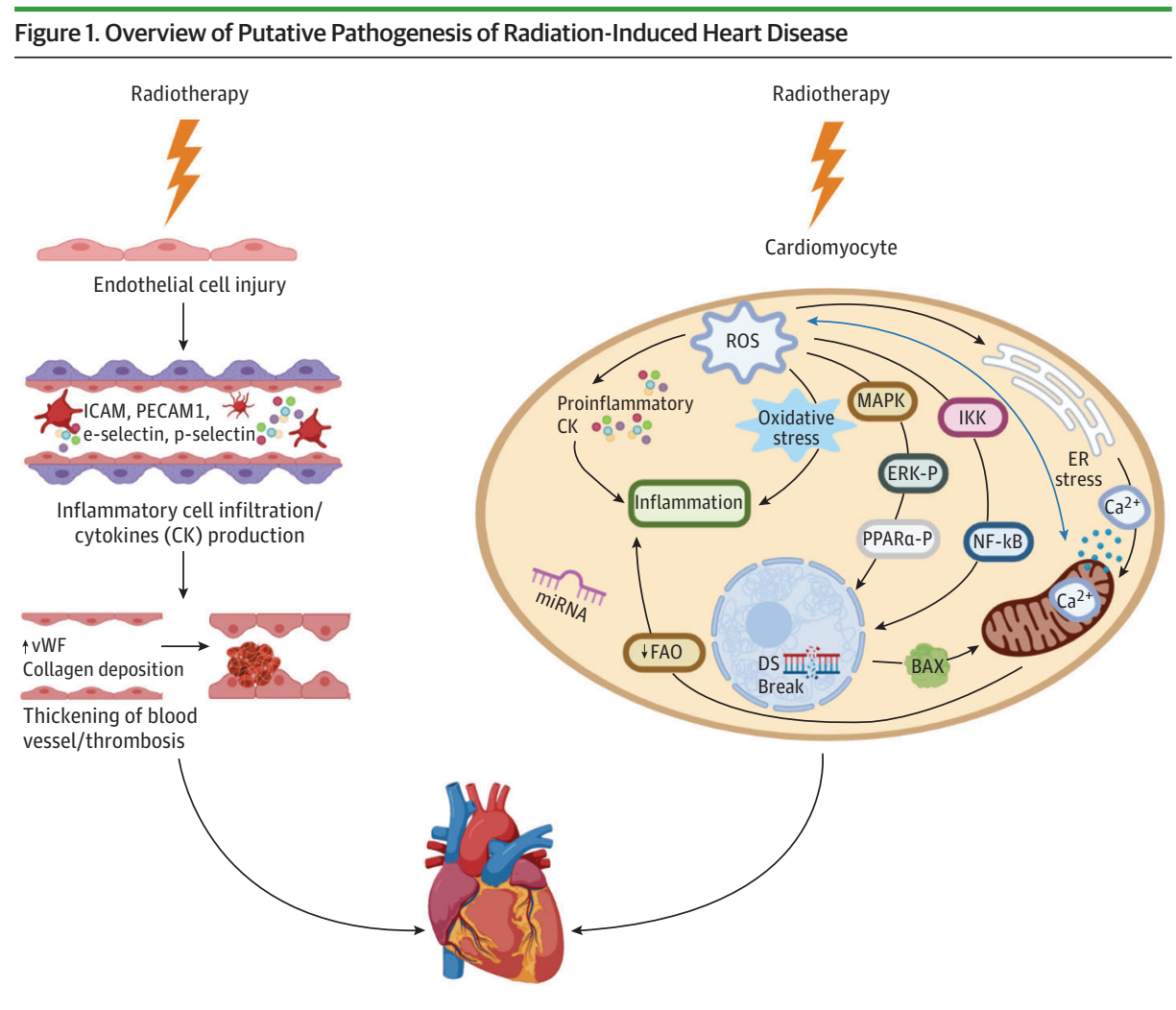

BAX indicates BCL2-associated $\mathrm{X}$ protein; Ca, calcium; CK, cytokines; DS, double-stranded; ER, endothelial reticulum; ERK-P, extracellular signal-regulated kinase; FAO, fatty acid oxidation; ICAM, intercellular adhesion molecule; IKK, inhibitor of nuclear factor $\mathrm{k} B$ kinase; MAPK, mitogen-activated protein kinase; miRNA, micro RNA; $\mathrm{NF}-\mathrm{kB}$, nuclear factor K-light-chain-enhancer of activated B cells; PECAM1, platelet endothelial cell adhesion molecule; PPARa-P, peroxisome proliferator-activated receptor a; ROS, reactive oxygen species; and vWF, Von Willebrand factor. This image was created using BioRender software (http://www.biorender.com). of fibrosis leading to ventricular dysfunction or restrictive cardiomyopathy. ${ }^{7}$ Even though the pathophysiological mechanisms of RIHD are not completely understood, it is known that multiple factors are involved in cardiac toxic effects. Early damage from RT is mostly associated with acute and chronic inflammatory changes, and late toxic effects are partly associated with both oxidative stress and inflammation. ${ }^{12}$ Macrovascular and microvascular injury, which develops in a multifactorial manner by endothelial cell damage, leads to activation of inflammatory and atherosclerotic responses. ${ }^{13}$ Several signaling pathways within the cardiomyocytes, including apoptosis and mitochondrial dysfunction, have been correlated with RIHD. ${ }^{14}$ Specifically, a vicious cycle of reactive oxygen species produced by mitochondria and $\mathrm{Ca}^{2+}$ release caused by the endoplasmic reticulum may be a factor in long-term toxic effects, which eventually leads to cell cycle arrest. ${ }^{15}$ MicroRNAs have also been found to be involved in the regulation of radiation-induced DNA damage and premature aging. ${ }^{16}$ An overview of the putative pathogenesis of RIHD is shown in Figure 1.

\section{Clinical Presentation and Assessment and Diagnosis}

Clinical presentations of RIHD (although cardiac injury may also have a subclinical presentation) include a spectrum of syndromes: pericardial disease (acute and delayed pericarditis, pericardial effusion, and constrictive pericarditis), coronary artery disease, myocardial infarction, valvular heart disease, and rhythm disturbances. ${ }^{17}$ Clinical signs are often indistinguishable from those of any other cause, representing a challenge for the clinician. These signs may include chest pain, shortness of breath, peripheral edema, fatigue, and arrhythmias (Table 1). ${ }^{11,17-21}$ The risk of RIHD development has been associated with the amount of substructures exposed to RT; age; the interval since RT; combination with drugs, including chemotherapy; and the presence of coexisting CV risk factors, such as hypertension, smoking status, high body mass index, dyslipidemia, and diabetes. ${ }^{3}$ Although the relative risk is substantial, the absolute risk for RT-related cardiac morbidity remains low compared with the general population. Moreover, modern technologies may have lower toxic effects given that patients with breast cancer are currently treated with lower radiation doses and advanced RT techniques, allowing doses to organs at risk to be kept far below the recommended constraints.

Different strategies have been implemented to detect RIHD. Early diagnosis can decrease long-term damage and thus the incidence of fatal events. Because RIHD is a lifelong risk, assessment requires long-term follow-up. ${ }^{18}$ However, clear recommendations are lacking on the modalities and intensity of heart disease screening and surveillance after RT. Three-dimensional echocardiography currently represents the criterion standard for detecting early signs of cardiac toxic effects. Early detection allows for analysis of both morphological characteristics and functional aspects, ${ }^{22}$ including left ventricular ejection fraction, global longitudinal strain, left ventricular diastolic function, left ventricular filling pressure, pulmonary pressure, and right ventricular function. ${ }^{23}$ Cardiac computed tomography is not routinely used, although it is more accurate than other techniques in detecting coronary artery calcification. ${ }^{24}$ Non-ionizing radiation modalities may be most appropriate because of concerns regarding cumulative radiation dose in patients with cancer; that is, cardiac computed tomography can expose patients to substantial radiation with each examination. Echocardiography provides additional information on car- 
Table 1. Timing, Symptoms, and Differential Diagnosis in Patients With Heart Disease After Radiation Treatment for Breast Cancer ${ }^{\mathrm{a}}$

\begin{tabular}{|c|c|c|c|}
\hline Timing & Heart disease & Symptom/sign & $\begin{array}{l}\text { Differential diagnosis } \\
\text { between RIHD and other causes }\end{array}$ \\
\hline \multirow[t]{3}{*}{5 to $20 y$} & \multirow[t]{3}{*}{ CAD } & \multirow{3}{*}{$\begin{array}{l}\text { Angina; myocardial infarction } \\
\text { Nonanginal chest pain (common } \\
\text { occurrence within } 3 \text { y) }\end{array}$} & Morphological structure \\
\hline & & & of RT-related CAD same as CAD \\
\hline & & & Assessment of time to symptoms \\
\hline \multirow[t]{7}{*}{10 y (symptomatic) } & \multirow{7}{*}{$\begin{array}{l}\text { Myocardial } \\
\text { injury }\end{array}$} & \multirow{7}{*}{$\begin{array}{l}\text { Restrictive cardiomyopathy } \\
\text { leading to diastolic dysfunction, } \\
\text { partially accompanied by a slight } \\
\text { reduction of LV systolic function }\end{array}$} & $\begin{array}{l}\text { onset and coexistent cardiac risk } \\
\text { factors }\end{array}$ \\
\hline & & & $\begin{array}{l}\text { Predictive parameters of RT-related } \\
\text { CAD: }\end{array}$ \\
\hline & & & Dose to the mediastinum $>30 \mathrm{~Gy}$ \\
\hline & & & Dose $35 \%$ >38 Gy (heart volume) \\
\hline & & & $\begin{array}{l}\text { Mean dose to } 5 \%>12 \mathrm{~Gy} \text { (heart } \\
\text { volume within the beam) }\end{array}$ \\
\hline & & & $\begin{array}{l}\text { Mean dose }>2.5 \text { Gy (whole-heart } \\
\text { volume) }\end{array}$ \\
\hline & & & RT to internal mammary nodes \\
\hline \multirow{5}{*}{$\begin{array}{l}4.5 \text { to } 11.5 \text { y } \\
\text { (asymptomatic) } \\
>16.5 \text { y (symptomatic) }\end{array}$} & \multirow[t]{5}{*}{$\begin{array}{l}\text { Valvular } \\
\text { disease }\end{array}$} & \multirow[t]{5}{*}{$\begin{array}{l}\text { Angina, syncope, dyspnea, } \\
\text { and/or heart failure }\end{array}$} & $\begin{array}{l}\text { For patients with breast cancer, } \\
\text { data are conflicting on the }\end{array}$ \\
\hline & & & $\begin{array}{l}\text { association of RT with valvular } \\
\text { dysfunction }\end{array}$ \\
\hline & & & $\begin{array}{l}\text { Incidence associated } \\
\text { with mediastinal RT doses of }>30 \mathrm{~Gy}\end{array}$ \\
\hline & & & $\begin{array}{l}\text { Increased risk with younger age } \\
\text { at irradiation }\end{array}$ \\
\hline & & & $\begin{array}{l}\text { Interruptions of elastic fibers } \\
\text { without rheumatic endocarditis } \\
\text { changes (pathology) }\end{array}$ \\
\hline \multirow[t]{2}{*}{6 mo to $20 \mathrm{y}$ (peak at $5 \mathrm{y})$} & \multirow{2}{*}{$\begin{array}{l}\text { Conduction } \\
\text { system } \\
\text { disease }\end{array}$} & \multirow{2}{*}{$\begin{array}{l}\text { All degrees of AV block, sick sinus } \\
\text { syndrome, bundle branch block, } \\
\text { prolongation of the QTc interval }\end{array}$} & $\begin{array}{l}\text { Presentation analogue to other } \\
\text { causes }\end{array}$ \\
\hline & & & $\begin{array}{l}\text { Rarely clinically relevant after-RT } \\
\text { exposure for breast cancer }\end{array}$ \\
\hline \multirow[t]{4}{*}{$\begin{array}{l}\text { During treatment (wk) or } \\
\text { after treatment up to } 10 \mathrm{y}\end{array}$} & \multirow[t]{4}{*}{$\begin{array}{l}\text { Pericardial } \\
\text { disease }\end{array}$} & \multirow{4}{*}{$\begin{array}{l}\text { Pleuritic chest pain, dyspnea, } \\
\text { fever, friction rub, and decreased } \\
\text { QRS voltage }\end{array}$} & $\begin{array}{l}\text { Predictive parameters of } \\
\text { RT-related pericardial disease: }\end{array}$ \\
\hline & & & Mean dose >26 Gy \\
\hline & & & Maximum dose $>47$ Gy \\
\hline & & & $\begin{array}{l}\text { Protein-rich exudates in the } \\
\text { pericardial sac and fibrin in the } \\
\text { mesothelial lining pericardial } \\
\text { cavity (pathology) }\end{array}$ \\
\hline
\end{tabular}

Abbreviations: AV, atrioventricular; $C A D$, coronary artery disease; LV, left ventricular; RIHD, radiation-induced heart disease; RT, radiotherapy. a Data from Darby et al, ${ }^{11} 2013$; Gagliardi et al, ${ }^{17}$ 2010; Darby et al, ${ }^{18}$ 2010; Larsen et al, ${ }^{19}$ 1992; and Carlson et al, ${ }^{20} 1991$ diac structure, valve function, hemodynamics, and physiological features that are not typically found with computed tomography scanning. The need to improve early detection has increased the use of cardiac magnetic resonance imaging. Although cardiac magnetic resonance imaging is not cost effective (because of limitations in availability and cost), it is capable of providing myocardial tissue characterization, including the detection of myocardial edema and fibrosis. ${ }^{25}$ Moreover, with the incorporation of global longitudinal strain, echocardiography is more sensitive to subtle damage of the myocardial ultrastructure that would otherwise be undetectable. The increase of both troponin $\mathrm{T}$ and $\mathrm{N}$-terminal probrain natriuretic peptide levels in the blood has been reported to be a highly sensitive and specific biomarker correlated with myocardial damage. ${ }^{26,27}$ In a more recent study, an increase in ST2 level, a marker of fibrosis, during postoperative RT was associated with worsening cardiac systolic function over time. ${ }^{28}$

\section{Toxic Effect Predictive Models}

Cardiac toxic effect rates from breast cancer randomized clinical trials are summarized in Table 2. ${ }^{78,29-38}$ Based on these studies, several predictive models have been proposed for estimating the risk of RIHD. ${ }^{39}$ Combining dosimetric data with toxic effect outcomes is fundamental to estimating the risk of cardiac toxic effects. ${ }^{11}$ Although no clear threshold (or safe) radiation dose exists for cardiac exposure, ${ }^{11}$ the mean heart dose (MHD) has been a pragmatic and relevant parameter for RIHD prediction for decades. ${ }^{11} \mathrm{~A} 7.4 \%$ increase in the relative risk of a major cardiac event has been estimated for each additional Gy of MHD. ${ }^{11,39}$ The Early Breast Cancer Trialists' Collaborative Group performed a systematic review of lung and heart doses in breast cancer regimens and individual data meta-analyses of 40781 women randomized to RT or no RT in 75 trials. ${ }^{40}$ The cause-specific mortality and excess rate ratios per Gy of MHD for cardiac mortality was 1.30 (95\% Cl, 1.15-1.46; $P<.001$ ) on the basis of 1253 cardiac deaths. Detailed analyses indicated $0.04(95 \% \mathrm{Cl}, 0.02-0.06)$ excess rate ratios per Gy whole-heart dose. Other research groups found that the relative risk of coronary artery disease increased by $16.5 \%$ per Gy of MHD during the first 9 years after irradiation. ${ }^{41}$ However, MHD might be considered an obsolete way to estimate the risk of heart damage; the newest research looks at the dose to individual substructures such as vessels. Replacing MHD with the proportion of the volume of the left ventricle receiving a dose of $5 \mathrm{~Gy}$ or more was found to be another reliable parameter that could improve the estimation of acute cardiac events. ${ }^{41}$ Because different doses at each cardiac substructure have distinct pathophysiological outcomes, different normal tissue complication probability models based on the anatomical dose distribution to estimate CV radiation risks also could be used. ${ }^{42}$ 


\begin{tabular}{|c|c|c|c|c|c|c|c|}
\hline \multirow[b]{2}{*}{ Source } & \multirow[b]{2}{*}{$\begin{array}{l}\text { Cardiac } \\
\text { end point }\end{array}$} & \multirow[b]{2}{*}{ Study design } & \multirow[b]{2}{*}{ Cases, No. } & \multirow[b]{2}{*}{ Cardiac events } & \multicolumn{2}{|c|}{ Cardiac events, No. (\%) } & \multirow[b]{2}{*}{ RT planning } \\
\hline & & & & & RT cohort & $\begin{array}{l}\text { No RT } \\
\text { cohort }\end{array}$ & \\
\hline \multirow[t]{3}{*}{ Rutqvist et al, ${ }^{29} 1992$} & \multirow{3}{*}{$\begin{array}{l}\text { Cardiac } \\
\text { mortality }\end{array}$} & \multirow[t]{3}{*}{ RT vs no RT } & \multirow{3}{*}{$\begin{array}{l}639 \text { (RT); } \\
321 \text { (no RT) }\end{array}$} & All events & $41(6.4)$ & $18(5.6)$ & \multirow[t]{3}{*}{$3 \mathrm{D}$} \\
\hline & & & & Death from myocardial infarction & $24(3.8)$ & $8(2.3)$ & \\
\hline & & & & Other cardiovascular disease & $17(2.7)$ & $10(2.8)$ & \\
\hline \multirow[t]{7}{*}{ Valagussa et al, ${ }^{30} 1994$} & \multirow{7}{*}{$\begin{array}{l}\text { Cardiac } \\
\text { events }^{\mathrm{a}}\end{array}$} & \multirow[t]{7}{*}{ RT vs no RT } & \multirow{7}{*}{$\begin{array}{l}360(\mathrm{RT}) ; \\
465 \text { (no RT) }\end{array}$} & All events & $63(17.5)$ & $25(5.4)$ & \multirow[t]{7}{*}{$2-D$} \\
\hline & & & & $\begin{array}{l}\text { ECG ST-segment and T-wave } \\
\text { transient abnormalities }\end{array}$ & $23(6.4)$ & $2(0.4)$ & \\
\hline & & & & $\begin{array}{l}\text { ECG signs suggestive of ischemic } \\
\text { heart disease }\end{array}$ & $11(3.1)$ & $6(1.3)$ & \\
\hline & & & & $\begin{array}{l}\text { Disturbances of heart rate and } \\
\text { rhythm and/or conduction }\end{array}$ & $10(2.8)$ & NR & \\
\hline & & & & Pericarditis & $2(0.6)$ & NR & \\
\hline & & & & Death form congestive heart failure & $2(0.6)$ & NR & \\
\hline & & & & Other cardiovascular diseases & $15(4.2)$ & NR & \\
\hline \multirow[t]{2}{*}{ Cuzick et al, ${ }^{7} 1994$} & \multirow{2}{*}{$\begin{array}{l}\text { Cardiac } \\
\text { mortality }\end{array}$} & \multirow[t]{2}{*}{ RT vs no RT } & \multirow{2}{*}{$\begin{array}{l}3935 \text { (RT); } \\
4006 \text { (no RT) }\end{array}$} & All events & $151(3.8)$ & $108(2.6)$ & \multirow[t]{2}{*}{$2-D$} \\
\hline & & & & Death from cardiac disease & $151(3.8)$ & $108(2.6)$ & \\
\hline \multirow[t]{2}{*}{ Houghton et al, ${ }^{31} 1994$} & \multirow{2}{*}{$\begin{array}{l}\text { Cardiac } \\
\text { mortality }\end{array}$} & RT vs no RT & 1400 (RT); & All events & $55(3.9)$ & $38(2.7)$ & $2-D$ \\
\hline & & & & Death from cardiac disease & 55 (3.9) & $38(2.7)$ & \\
\hline Højris et al, ${ }^{32} 1999$ & Cardiac & RT vs no RT & 1525 (RT); & All events & $89(5.8)$ & $93(6.1)$ & $2-D$ \\
\hline & events $^{\mathrm{d}}$ & & & Ischemic heart disease & $46(3.0)$ & $49(3.2)$ & \\
\hline & & & & Acute myocardial infarction & $26(1.7)$ & $22(1.4)$ & \\
\hline & & & & Death from ischemic heart disease & $12(0.8)$ & $13(0.9)$ & \\
\hline & & & & Death from myocardial infarction & $5(0.3)$ & $9(0.6)$ & \\
\hline Woodward et al, ${ }^{33} 2003$ & Cardiac & RT vs no RT & 470 (RT); & All events & $12(2.6)$ & $5(0.5)$ & $2-D$ \\
\hline & events & & 1031 (no RI) & Death from myocardial infarction & $8(1.7)$ & $5(0.5)$ & \\
\hline Clarke et al, ${ }^{8} 2005$ & Cardiac & RT vs no RT & 32800 & All events & $2961(9.0)$ & NR & NR \\
\hline & mortality ${ }^{\circ}$ & & & Death from circulatory disease & $1510(4.6)$ & & \\
\hline & & & & Death from heart disease & $1106(3.4)$ & & \\
\hline & & & & Death from stroke & $345(1.0)$ & & \\
\hline Halyard et al, ${ }^{34} 2009$ & Cardiac & RT vs no RT & 1418 (RT); & All events & $23(1.6)$ & $16(3.0)$ & $3 \mathrm{D}$ \\
\hline & & & & Congestive heart failure & $22(1.5)$ & $14(2.7)$ & \\
\hline & & & & Death from cardiac disease & $1(0.1)$ & $2(0.4)$ & \\
\hline Killander et al, ${ }^{35} 2014$ & Cardiac & RT vs no RT & $682(\mathrm{RT})$ & All events & $90(13.2)$ & $26(7.2)$ & $2 \mathrm{D}$ \\
\hline & mortality $^{\mathrm{d}}$ & & $358($ no RI) & Death from cardiac disease & $90(13.2)$ & $26(7.2)$ & \\
\hline Hennequin et al, ${ }^{36} 2013$ & Cardiac & IM-MS RT & 1334 & All events & $26(1.9)$ & NA & $2 \mathrm{D}$ \\
\hline & & & & Cardiac disease, IM-MS RT & $15(1.1)$ & & \\
\hline & & & & Cardiac disease, no IM-MS RT & $11(0.8)$ & & \\
\hline Poortmans et al, ${ }^{37} 2015$ & Cardiac & IM-MS RT & 3866 & All events & $234(6.0)$ & NA & $2 \mathrm{D}$ to $3 \mathrm{D}$ \\
\hline & events $^{\mathrm{D}}$ & vs no IMI-IMS RI & & Cardiac disease, IM-MS RT & $125(3.2)$ & & \\
\hline & & & & Cardiac disease, no IM-MS RT & $109(2.8)$ & & \\
\hline Whelan et al, ${ }^{38} 2015$ & Cardiac & Regional RT & 1820 & All events & $12(0.6)$ & NA & $2 \mathrm{D}$ to $3 \mathrm{D}$ \\
\hline & events $^{\mathrm{D}}$ & vs no regional RT & & Cardiac disease, regional RT & $8(0.4)$ & & \\
\hline & & & & Cardiac disease, no regional RT & $4(0.2)$ & & \\
\hline $\begin{array}{l}\text { Abbreviations: 2D, 2-dimen } \\
\text { IM-MS, internal mammary } \\
\text { NR, not reported; RT, radio }\end{array}$ & $\begin{array}{l}\text { ional; 3D, 3-d } \\
\text { hd medial sup } \\
\text { eerapy. }\end{array}$ & $\begin{array}{l}\text { ensional; ECG, elect } \\
\text { lavicular nodes; NA }\end{array}$ & $\begin{array}{l}\text { rocardiogram; } \\
\text {, not applicable; }\end{array}$ & $\begin{array}{l}\text { a Primary end point of the study. } \\
\text { b Secondary end point of the study. }\end{array}$ & & & \\
\hline
\end{tabular}

\section{Prevention and Treatment Strategies}

Heart Dose and RT Techniques

Because of the increased awareness of the risk of RT-related CV disease, the breast cancer RT community has strived to decrease heart dose. Modern RT presents considerably fewer risks than the techniques from 20 years ago, ${ }^{40}$ and evidence shows that heart doses are decreasing. ${ }^{43}$ Traditionally, the most used technique for whole-breast irradiation is 3-dimensional conformal RT (3D-CRT) with 2 opposing tangential photon beams. However, more advanced techniques, including intensity-modulated radiation therapy (IMRT) and volumetric modulated arc therapy (VMAT), are increasingly used. These advanced techniques use multiple beams 
A Free breathing

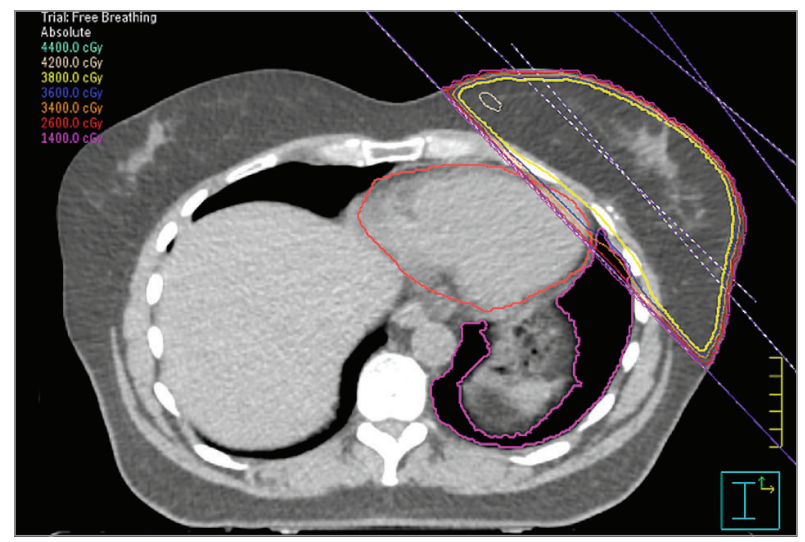

B Deep inspiration breath hold

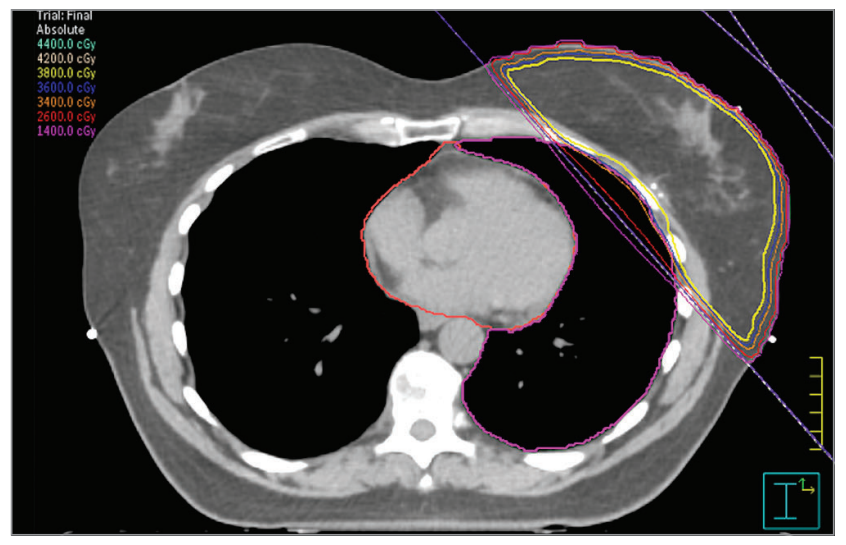

Both images represent the same anatomical level within the breast tissue, but the inflation of the lungs causes the heart (outlined in red) to rotate away from the chest wall. Notice that the tangential radiation beams (purple) intersect the heart (hence deposit dose) in free breathing but not in DIBH. Image reproduced with permission from Katherine Jones, MSc, The Christie NHS Foundation Trust, Manchester, England.

and computer-driven optimization to achieve highly conformal dose distributions around often complex target volumes, frequently leading to a larger volume of nontarget tissue receiving a low-dose bath. ${ }^{44}$ Hybrid techniques (combination of 3D-CRT and IMRT or VMAT) have been proposed as a possible compromise. ${ }^{45}$ The simplest and most common implementation of hybrid RT is often called field-in-field technique or tangential IMRT and can improve dose homogeneity (important for cosmesis) without increasing the number of beam angles. ${ }^{46,47}$ Multifield (multiangle) IMRT and VMAT techniques may further improve homogeneity in complex cases, but they are not always associated with a reduction in heart dose compared with tangential techniques (3D-CRT or field-in-field technique). ${ }^{46,48-50}$

Heart dose varies with patient anatomy, cancer laterality, and the inclusion of nodal regions as target volume. ${ }^{51} \mathrm{~A}$ systematic review of published breast RT studies showed that including the internal mammary chain increases MHD by about 4 Gy, but does so with large variations even within apparently similar techniques. $^{52}$

Several national and international groups have strived to provide recommendations on dose constraints to the whole heart (eTable 1 in the Supplement), but a general consensus is lacking. In addition, the constraints that referred to 25 -fraction and 15 - to 16 fraction regimens need to be revised for recently introduced extreme hypofractionation regimens (ie, $5.2 \mathrm{~Gy} \times 5$ fractions). ${ }^{53}$ For accelerated partial breast irradiation treatments, the dose constraints reflect the low doses delivered to the heart because of the decreased target volume. Recent reports include dose constraints at cardiac substructures, such as the left anterior descending artery or left ventricle. More substructures may be included as the understanding evolves and as advanced tools (eg, automatic delineation using artificial intelligence) become more widely available. ${ }^{54}$ Those constraints serve as guidelines; therefore, a balance between target coverage and organs-at-risk doses that are as low as reasonably achievable must be reached in each patient according to the patient's anatomy and risk factors.
Respiratory control, often referred to as (moderately) deep inspiration breath hold, is arguably the most common approach used to decrease the dose to the heart (Figure 2). At deep inspiration, the inflation of the lungs increases the distance between the heart and the chest wall, decreasing the dose to the heart ${ }^{52}$ and the lungs $5^{55}$ while facilitating tumor coverage. ${ }^{56}$ Positioning the patient prone or on the side can also be beneficial for patients with large, pendulous breasts, requiring no regional irradiation ${ }^{52}$; however, this positioning requires dedicated equipment and poses additional challenges in patient setup. ${ }^{57}$ Deep inspiration breath hold is compatible with several RT techniques, such as IMRT or VMAT and proton beam therapy (PBT). Proton beam therapy can also decrease the dose to the heart, which can be useful in select patients such as those with pectus excavatum. ${ }^{58}$ However, increased skin toxic effects and suboptimal cosmetic results have been reported with the use of $\mathrm{PBT}{ }^{59,60}$ and were mostly associated with the use of older PBT techniques. Similar to photon-based RT, PBT technology has evolved dramatically in the past decade: newer PBT facilities include advanced intensity modulation (eg, pencil beam scanning) and on-board image guidance. Future clinical research is needed to provide evidence of the role of this complex and expensive treatment modality in breast cancer (Figure 3 ).

The change of fractionation regimens (eg, from $50 \mathrm{~Gy} / 25$ regimen to $40 \mathrm{~Gy} / 15$ regimen) will lead to decreases in physical and radiobiologically equivalent heart doses. Appelt et al ${ }^{61}$ compared heart dose distributions for different hypofractionation schedules (START [UK Standardisation of Breast Radiotherapy] A and B trials ${ }^{62}$ and the Canadian trial [Hypofractionated Radiotherapy Post-Lumpectomy in Women With Node Negative Breast Cancer $]^{63}$ ) with the conventional 50 Gy per 25 regimen. Appelt et $\mathrm{al}^{61}$ found that the dose to the heart, which was adjusted for fraction size using the linear quadratic model, was generally lower after hypofractionated compared with conventionally fractionated schedules, even for low values of a or $\beta$. However, whether this decrease will lead to a reduction in cardiac toxic effects remains unknown. 
Figure 3. An Example of Dose Distribution From Photon Volumetric Modulated Arc Therapy (VMAT) Compared With Pencil Beam Scanning Proton Therapy for a Patient Treated for Breast and Internal Mammary Nodes in Free Breathing

A Photon VMAT plan

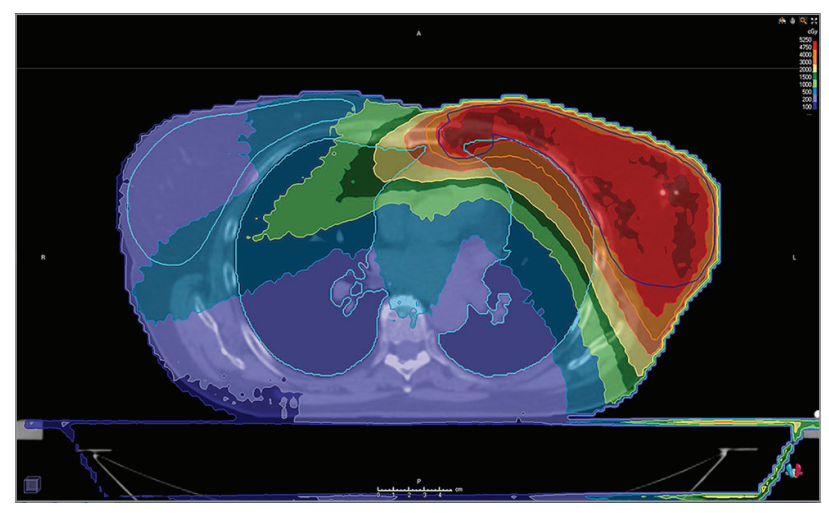

B Pencil beam scanning proton therapy

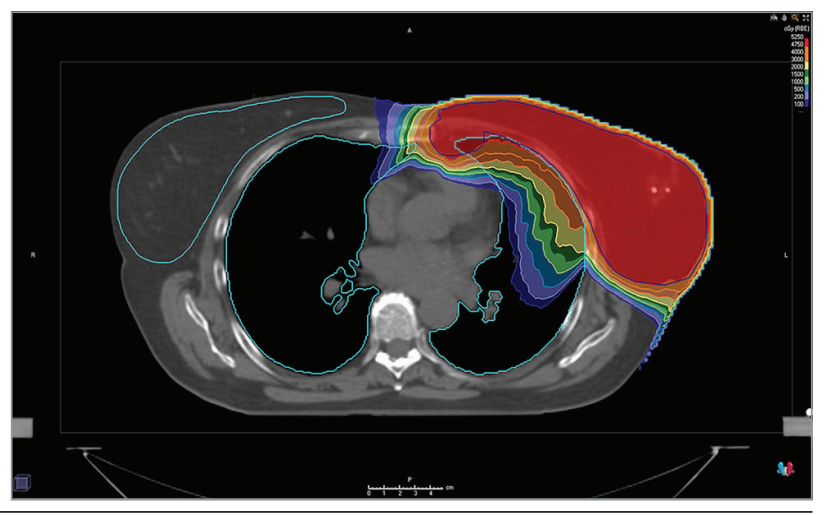

Image reproduced with permission from Giorgio Cartechini, MSc, University of Trento, and Marco Schwarz, MSc, PhD, Proton Therapy Center, Trento, Italy.

\section{Precision Medicine and De-escalation of Treatments}

Several de-escalation approaches have been evaluated over time as strategies to decrease the burden of treatments while maintaining equivalent efficacy outcomes. Both tumor stage and biological qualities are factors in survival outcomes for breast cancer and should be the cornerstone of precision medicine. ${ }^{64}$ Omission of postoperative RT for patients aged 65 years or older (or for frail patients with considerable comorbidities) with early-stage hormone receptorpositive, node-negative, low-risk breast cancer can be considered, providing that adjuvant endocrine therapy is prescribed. ${ }^{65}$

In several countries, moderate hypofractionation represents the standard of care for whole breast irradiation after breastconserving surgery. ${ }^{63}$ Currently, further reduction of treatment times might be expected given that delivering 26 Gy of whole breast irradiation in 5 fractions has been demonstrated to be equivalent at 5 years with 40 Gy in 15 fractions for whole-breast and chest wall irradiation. ${ }^{53}$ Conversely, given some of the long-term outcomes observed in the FAST trial (FAST Phase III Trial of Radiotherapy Hypofractionation for Treatment of Early Breast Cancer) and the established track record of 40 to 42.5 Gy in 15 to 16 fractions, ${ }^{66}$ further research and a wide consensus are needed before a 5 -fraction regimen can be adopted in our clinical practice. Partial-breast irradiation has been introduced as an alternative treatment approach to whole-breast irradiation for selected low-risk patients. Several large phase 3 trials have demonstrated the noninferiority of partial breast vs whole-breast irradiation in terms of local recurrence and similar or decreased toxic effect using different available techniques. ${ }^{67-70}$ Physical RT properties are different for each partialbreast irradiation technique, substantially altering dose distribution, irradiated volumes, dose homogeneity, and skin doses, all of which may have different clinical outcomes. ${ }^{71}$ Specific studies focusing on technical concerns, safety profile, and new relevant end points for patients at low risk of recurrence, such as quality of life, will further help the decision-making process.

\section{Pharmacological Interventions}

There has been an ongoing interest in biomedical substances that may counteract the adverse effects of ionizing radiation. Studies suggest that RIHD can be prevented by using some drugs, including statins, angiotensin-converting enzyme inhibitors, and antioxidants (eTable 2 in the Supplement). ${ }^{72,73}$ In the acute response period after radiation exposure to normal tissues, statins can inhibit the activation of transcription factor NF-KB (nuclear factor K-light-chainenhancer of activated $B$ cells). ${ }^{72}$ Angiotensin-converting enzyme inhibitors impede the production of reactive oxygen species to decrease myocardial injury and increase the production of nitric oxide to protect vascular cells by reducing the adverse effects on the bradykinin system. ${ }^{73}$ Moreover, several antioxidants have shown decreased adverse cardiac effects when administered before irradiation in preclinical settings. Several therapeutic targets are being explored, including anti-inflammatory, antifibrotic, and antiapoptotic mediators (eTable 2 in the Supplement). Given its antioxidant and antifibrotic properties, metformin hydrochloride has been shown to reduce radiation-induced cardiac toxic effects, possibly minimizing radiation damage to the heart or coronary artery. ${ }^{74}$ Overall, the benefits of several compounds have been demonstrated in preclinical studies, but data on these drugs in patients with RIHD are limited.

\section{Discussion}

Although radiation treatments for breast cancer have been optimized over time, long-term follow-up has shown that patients with breast cancer may have an increased risk of CV disease. Many of the reported studies are old, however, and do not apply to the modern RT era, in which the cardiac doses have decreased dramatically with new techniques (ie, IMRT, VMAT, and deep inspiration breath hold), and the current risk of cardiac events has become substantially low. Stroke and heart disease have similar pathophysiological functions in patients with cancer, and the incidence of both conditions increases with RT. ${ }^{2,21}$ However, clear recommendations are lacking on the modalities and intensity of CV disease screening and surveillance in patients with breast cancer after exposure to ionizing radiation.

Patients with breast cancer are often treated with cardiotoxic agents, in addition to RT (ie, anthracycline-based chemotherapy and 
anti-ERBB2 therapies). The risk of cardiac toxic effects is higher in these patients, suggesting a synergistic association with cardiac risk. Preclinical evidence showed that RIHD might be modulated by the programmed cell death 1 axis and that programmed cell death 1 blockade should be administered with careful RT planning. ${ }^{75}$

Respiratory control is arguably the most practical and successful approach to minimizing the radiation dose to the heart. Deescalation approaches decrease the burden of treatments, including the radiation dose to the organs at risk, thereby lowering late $\mathrm{CV}$ complications. Treatment prescription, including target volume selection and dose coverage, should be individually balanced on the basis of estimated risks of both tumor and CV risk factors. This balance may result in accepting underdosing and/or omitting parts of the target volumes, such as internal mammary nodes, in patients in whom CV risk factors prevail, whereas in others increased heart doses might be accepted in case of high-risk tumor factors.

Although several pharmacological cardioprevention strategies have been identified for patient candidates to receive an anti- cancer therapy with cardiotoxic agents, ${ }^{4}$ no feasible treatment for $\mathrm{RIHD}$ is currently available in routine clinical practice. Strategies to decrease CV risk factors (ie, blood lipids, arterial tension, obesity, and diabetes) should be handled with even more precision in patients who are being treated for cancer, depending on their CV risk factors and oncological prognosis.

\section{Conclusions}

Adopting strategies aimed at decreasing the cardiac RT dose, combined with advances in pharmacological cardiological interventions, should lead to both a decrease in the absolute risk of toxic effects and a relative increase in cardiac toxic effects for patients who undergo irradiation. Patient awareness of the cardiac risks associated with RT for breast cancer and multidisciplinary counseling are crucial in the management of patients with breast cancer.

\section{ARTICLE INFORMATION}

Accepted for Publication: September 29, 2020.

Published Online: March 4, 2021.

doi:10.1001/jamaoncol.2020.7468

Author Affiliations: Department of Experimental and Clinical Biomedical Sciences Mario Serio, University of Florence, Florence, Italy (Meattini, Livi); Radiation Oncology Unit, Oncology Department, Azienda Ospedaliero Universitaria Careggi, Florence, Italy (Meattini, Becherini, Livi); Department of Radiation Oncology, Iridium Kankernetwerk, Wilrijk-Antwerp, Belgium (Poortmans); University of Antwerp, Faculty of Medicine and Health Sciences, Wilrijk-Antwerp. Belgium (Poortmans); Division of Cancer Sciences, Faculty of Biology, Medicine and Health, The University of Manchester, The Christie NHS Foundation Trust, Manchester, United Kingdom (Aznar); Nuffield Department of Population Health, University of Oxford, Oxford, United Kingdom (Aznar); Department of Radiation Oncology, Istituto di Ricovero e Cura a Carattere Scientifico (IRCCS) San Matteo Polyclinic Foundation, Pavia, Italy (Bonzano); PhD School in Experimental Medicine, University of Pavia, Pavia, Italy (Bonzano): Cardioncology Unit, European Institute of Oncology, IRCCS, Milan, Italy (Cardinale); Cardio-Oncology Center of Excellence, Washington University in St Louis, St Louis, Missouri (Lenihan); Medical Physics Unit, Azienda Ospedaliero Universitaria Careggi, Florence, Italy (Marrazzo); Division of Early Drug Development, European Institute of Oncology, IRCCS, Milan, Italy (Curigliano); Department of Oncology and Hemato-Oncology, University of Milan, Milan, Italy (Curigliano).

Author Contributions: Dr Meattini had full access to all of the data in the study and takes responsibility for the integrity of the data and the accuracy of the data analysis. Drs Meattini and Poortmans contributed equally to the work. Concept and design: Meattini, Poortmans, Cardinale, Lenihan, Marrazzo, Curigliano, Livi. Acquisition, analysis, or interpretation of data: Meattini, Poortmans, Aznar, Becherini, Bonzano, Curigliano.

Drafting of the manuscript: Meattini, Poortmans,
Aznar, Becherini, Bonzano, Cardinale, Marrazzo, Curigliano.

Critical revision of the manuscript for important intellectual content: Meattini, Poortmans, Aznar, Becherini, Cardinale, Lenihan, Marrazzo, Curigliano, Livi. Administrative, technical, or material support: Meattini, Poortmans, Aznar, Becherini, Curigliano. Supervision: Meattini, Poortmans, Cardinale, Lenihan, Curigliano, Livi.

Other - bibliographic research and manuscript writing, figures and tables: Marrazzo. Other: Curigliano.

Conflict of Interest Disclosures: Dr Meattini reported serving on the advisory boards of Lilly, Pfizer, Roche, and Novartis outside the submitted work. Dr Poortmans reported being a medical advisor for Sordina IORT Technologies SpA. Dr Aznar reported receiving grants from the National Institute for Health Research Manchester Biomedical Research Centre and from the Cancer Research UK RadNet Manchester during the conduct of the study. Dr Lenihan reported receiving grants from Myocardial Solutions Inc outside the submitted work. Dr Marrazzo reported receiving financial support from Elekta to participate in the European Society for Radiotherapy and Oncology Congress. Dr Curigliano reported receiving grants from Merck and other from Roche, Novartis, Daiichi Sankyo, AstraZeneca, Lilly, Pfizer, Merck, BMS, and Ellipsis outside the submitted work. No other disclosures were reported.

Additional Contributions: Katherine Jones, MSc, The Christie NHS Foundation Trust; Giorgio Cartechini, MSc, University of Trento; and Marco Schwarz, MSc, PhD, Proton Therapy Center, provided permission to reprint the images in figures 2 and 3 . These individuals received no additional compensation, outside of their usual salary, for their contributions.

\section{REFERENCES}

1. Gilchrist SC, Barac A, Ades PA, et al; American Heart Association Exercise, Cardiac Rehabilitation, and Secondary Prevention Committee of the Council on Clinical Cardiology; Council on Cardiovascular and Stroke Nursing; and Council on Peripheral Vascular Disease. Cardio-oncology rehabilitation to manage cardiovascular outcomes in cancer patients and survivors: a scientific statement from the American Heart Association. Circulation. 2019;139(21):e997-e1012. doi:10.1161/CIR 0000000000000679

2. Stoltzfus KC, Zhang Y, Sturgeon K, et al. Fatal heart disease among cancer patients. Nat Commun. 2020;11(1):2011. doi:10.1038/s41467-020-15639-5

3. Virani SS, Alonso A, Benjamin EJ, et al; American Heart Association Council on Epidemiology and Prevention Statistics Committee and Stroke Statistics Subcommittee. Heart disease and stroke statistics-2020 update: a report from the American Heart Association. Circulation. 2020;141(9): e139-e596. doi:10.1161/CIR.0000000000000757

4. Curigliano G, Lenihan D, Fradley M, et al; ESMO Guidelines Committee. Management of cardiac disease in cancer patients throughout oncological treatment: ESMO consensus recommendations. Ann Oncol. 2020;31(2):171-190. doi:10.1016/j. annonc.2019.10.023

5. Cardinale D, Colombo A, Bacchiani G, et al. Early detection of anthracycline cardiotoxicity and improvement with heart failure therapy. Circulation. 2015;131(22):1981-1988. doi:10.1161/ CIRCULATIONAHA.114.013777

6. Slamon D, Eiermann W, Robert N, et al; Breast Cancer International Research Group. Adjuvant trastuzumab in HER2-positive breast cancer. NEngl J Med. 2011;365(14):1273-1283. doi:10.1056/ NEJMoa0910383

7. Cuzick J, Stewart $H$, Rutqvist L, et al. Cause-specific mortality in long-term survivors of breast cancer who participated in trials of radiotherapy. J Clin Oncol. 1994;12(3):447-453. doi:10.1200/JCO.1994.12.3.447

8. Clarke M, Collins R, Darby S, et al; Early Breast Cancer Trialists' Collaborative Group (EBCTCG). Effects of radiotherapy and of differences in the extent of surgery for early breast cancer on local recurrence and 15-year survival: an overview of the randomised trials. Lancet. 2005;366(9503): 2087-2106. doi:10.1016/S0140-6736(05)67887-7

9. Darby S, McGale P, Correa C, et al; Early Breast Cancer Trialists' Collaborative Group (EBCTCG). Effect of radiotherapy after breast-conserving surgery on 10 -year recurrence and 15 -year breast 
cancer death: meta-analysis of individual patient data for 10,801 women in 17 randomised trials. Lancet. 2011;378(9804):1707-1716. doi:10.1016/ S0140-6736(11)61629-2

10. Aznar MC, Korreman SS, Pedersen AN, Persson GF, Josipovic M, Specht L. Evaluation of dose to cardiac structures during breast irradiation. Br J Radiol. 2011;84(1004):743-746. doi:10.1259/ bjr/12497075

11. Darby SC, Ewertz M, McGale P, et al. Risk of ischemic heart disease in women after radiotherapy for breast cancer. N Engl J Med. 2013;368(11): 987-998. doi:10.1056/NEJMoa1209825

12. Zhao W, Robbins ME. Inflammation and chronic oxidative stress in radiation-induced late normal tissue injury: therapeutic implications. Curr Med Chem. 2009;16(2):130-143. doi:10.2174/ 092986709787002790

13. Baselet $B$, Rombouts $C$, Benotmane AM Baatout $S$, Aerts A. Cardiovascular diseases related to ionizing radiation: the risk of low-dose exposure (review). Int J Mol Med. 2016;38(6):1623-1641. doi:10.3892/ijmm.2016.2777

14. Wang $\mathrm{H}$, Wei J, Zheng $\mathrm{Q}$, et al.

Radiation-induced heart disease: a review of classification, mechanism and prevention. Int J Biol Sci. 2019;15(10):2128-2138. doi:10.7150/ijbs.35460

15. Yamamori T, Yasui H, Yamazumi M, et al. lonizing radiation induces mitochondrial reactive oxygen species production accompanied by upregulation of mitochondrial electron transport chain function and mitochondrial content under control of the cell cycle checkpoint. Free Radic Biol Med. 2012;53(2):260-270. doi:10.1016/j.

freeradbiomed.2012.04.033

16. Viczenczova C, Kura B, Egan Benova T, et al. Irradiation-induced cardiac connexin-43 and miR-21 responses are hampered by treatment with atorvastatin and aspirin. Int J Mol Sci. 2018;19(4): E1128. doi:10.3390/ijms19041128

17. Gagliardi G, Constine LS, Moiseenko V, et al. Radiation dose-volume effects in the heart. Int J Radiat Oncol Biol Phys. 2010;76(3 suppl):S77-S85 doi:10.1016/j.ijrobp.2009.04.093

18. Darby SC, Cutter DJ, Boerma M, et al. Radiation-related heart disease: current knowledge and future prospects. Int J Radiat Oncol Biol Phys. 2010;76(3):656-665. doi:10.1016/j.jirobp.2009. 09.064

19. Larsen RL, Jakacki RI, Vetter VL, Meadows AT, Silber JH, Barber G. Electrocardiographic changes and arrhythmias after cancer therapy in children and young adults. Am J Cardiol. 1992;70(1):73-77. doi:10.1016/0002-9149(92)91393-।

20. Carlson RG, Mayfield WR, Normann S, Alexander JA. Radiation-associated valvular disease. Chest. 1991;99(3):538-545. doi:10.1378/ chest.99.3.538

21. Zaorsky NG, Zhang Y, Tchelebi LT, Mackley HB Chinchilli VM, Zacharia BE. Stroke among cancer patients. Nat Commun. 2019;10(1):5172. doi:10. 1038/s41467-019-13120-6

22. Jacob S, Pathak A, Franck D, et al. Early detection and prediction of cardiotoxicity after radiation therapy for breast cancer: the BACCARAT prospective cohort study. Radiat Oncol. 2016;11:54. doi:10.1186/s13014-016-0627-5

23. Yu AF, Ho AY, Braunstein LZ, et al. Assessment of early radiation-induced changes in left ventricular function by myocardial strain imaging after breast radiation therapy. J Am Soc Echocardiogr. 2019;32(4):521-528. doi:10.1016/j.echo.2018.12.009

24. Milgrom SA, Varghese $B$, Gladish GW, et al. Coronary artery dose-volume parameters predict risk of calcification after radiation therapy. J Cardiovasc Imaging. 2019;27(4):268-279. doi:10.4250/jcvi.2019.27.e38

25. Karamitsos TD, Arvanitaki A, Karvounis $H$, Neubauer S, Ferreira VM. Myocardial tissue characterization and fibrosis by imaging. JACC Cardiovasc Imaging. 2020;13(5):1221-1234. doi:10. 1016/j.jcmg.2019.06.030

26. Skyttä T, Tuohinen S, Boman E, Virtanen V, Raatikainen P, Kellokumpu-Lehtinen PL. Troponin T-release associates with cardiac radiation doses during adjuvant left-sided breast cancer radiotherapy. Radiat Oncol. 2015;10:141. doi:10. 1186/s13014-015-0436-2

27. D'Errico MP, Grimaldi L, Petruzzelli MF, et al. $\mathrm{N}$-terminal pro-B-type natriuretic peptide plasma levels as a potential biomarker for cardiac damage after radiotherapy in patients with left-sided breast cancer. Int J Radiat Oncol Biol Phys. 2012;82(2): e239-e246. doi:10.1016/j.jirobp.2011.03.058

28. Aula H, Skyttä T, Tuohinen S, et al. ST2 levels increased and were associated with changes in left ventricular systolic function during a three-year follow-up after adjuvant radiotherapy for breast cancer. Breast. 2020;49:183-186. doi:10.1016/ j.breast.2019.12.001

29. Rutqvist LE, Lax I, Fornander $T$, Johansson $H$. Cardiovascular mortality in a randomized trial of adjuvant radiation therapy versus surgery alone in primary breast cancer. Int J Radiat Oncol Biol Phys. 1992;22(5):887-896. doi:10.1016/0360-3016(92) 90784-F

30. Valagussa $P$, Zambetti M, Biasi S, Moliterni A, Zucali R, Bonadonna G. Cardiac effects following adjuvant chemotherapy and breast irradiation in operable breast cancer. Ann Oncol. 1994;5(3) 209-216. doi:10.1093/oxfordjournals.annonc. a058795

31. Houghton J, Baum M, Haybittle JL; The Closed Trials Working Party of the CRC Breast Cancer Trials Group. Role of radiotherapy following total mastectomy in patients with early breast cancer World J Surg. 1994;18(1):117-122. doi:10.1007/ BF00348201

32. Højris I, Overgaard M, Christensen JJ, Overgaard J; Radiotherapy Committee of the Danish Breast Cancer Cooperative Group. Morbidity and mortality of ischaemic heart disease in high-risk breast-cancer patients after adjuvant postmastectomy systemic treatment with or without radiotherapy: analysis of DBCG $82 \mathrm{~b}$ and 82c randomised trials. Lancet. 1999;354(9188): 1425-1430. doi:10.1016/S0140-6736(99)02245-X 33. Woodward WA, Strom EA, McNeese MD, et al. Cardiovascular death and second non-breast cancer malignancy after postmastectomy radiation and doxorubicin-based chemotherapy. Int J Radiat Oncol Biol Phys. 2003;57(2):327-335. doi:10.1016/ S0360-3016(03)00594-7

34. Halyard MY, Pisansky TM, Dueck AC, et al. Radiotherapy and adjuvant trastuzumab in operable breast cancer: tolerability and adverse event data from the NCCTG phase III Trial N9831. J Clin Oncol. 2009;27(16):2638-2644. doi:10.1200/ JCO.2008.17.9549
35. Killander $F$, Anderson $H$, Kjellén E, Malmström $P$. Increased cardio and cerebrovascular mortality in breast cancer patients treated with postmastectomy radiotherapy--25 year follow-up of a randomised trial from the South Sweden Breast Cancer Group. Eur J Cancer. 2014;50(13):2201-2210. doi:10.1016/ j.ejca.2014.04.033

36. Hennequin C, Bossard N, Servagi-Vernat S, et al. Ten-year survival results of a randomized trial of irradiation of internal mammary nodes after mastectomy. Int J Radiat Oncol Biol Phys. 2013;86 (5):860-866. doi:10.1016/j.jijrobp.2013.03.021

37. Poortmans PM, Collette S, Kirkove C, et al; EORTC Radiation Oncology and Breast Cancer Groups. Internal mammary and medial supraclavicular irradiation in breast cancer. NEngl J Med. 2015;373(4):317-327. doi:10.1056/ NEJMoa1415369

38. Whelan TJ, Olivotto IA, Parulekar WR, et al; MA.20 Study Investigators. Regional noda irradiation in early-stage breast cancer. N Engl J Med. 2015;373(4):307-316. doi:10.1056/NEJMoa1415340

39. Jacob $S$, Camilleri J, Derreumaux $S$, et al. Is mean heart dose a relevant surrogate parameter of left ventricle and coronary arteries exposure during breast cancer radiotherapy: a dosimetric evaluation based on individually-determined radiation dose (BACCARAT study). Radiat Oncol. 2019;14(1):29. doi:10.1186/s13014-019-1234-z

40. Taylor C, Correa C, Duane FK, et al; Early Breast Cancer Trialists' Collaborative Group. Estimating the risks of breast cancer radiotherapy: evidence from modern radiation doses to the lungs and heart and from previous randomized trials. J Clin Oncol. 2017; 35(15):1641-1649. doi:10.1200/JCO.2016.72.0722

41. van den Bogaard VA, Ta BD, van der Schaaf $A$ et al. Validation and modification of a prediction model for acute cardiac events in patients with breast cancer treated with radiotherapy based on three-dimensional dose distributions to cardiac substructures. J Clin Oncol. 2017;35(11):1171-1178. doi:10.1200/JCO.2016.69.8480

42. Trott $K R$, Doerr $W$, Facoetti $A$, et al. Biological mechanisms of normal tissue damage: importance for the design of NTCP models. Radiother Oncol. 2012;105(1):79-85. doi:10.1016/j.radonc.2012.05.008 43. Pierce LJ, Feng M, Griffith KA, et al; Michigan Radiation Oncology Quality Consortium. Recent time trends and predictors of heart dose from breast radiation therapy in a large quality consortium of radiation oncology practices. Int $J$ Radiat Oncol Biol Phys. 2017;99(5):1154-1161. doi:10. 1016/j.jijrobp.2017.07.022

44. Lohr F, El-Haddad M, Dobler B, et al. Potential effect of robust and simple IMRT approach for left-sided breast cancer on cardiac mortality. Int J Radiat Oncol Biol Phys. 2009;74(1):73-80. doi:10 1016/j.jijrobp.2008.07.018

45. Balaji K, Balaji Subramanian S, Sathiya K, Thirunavukarasu M, Anu Radha C, Ramasubramanian V. Hybrid planning techniques for hypofractionated whole-breast irradiation using flattening filter-free beams. Strahlenther Onkol. 2020;196(4):376-385. doi:10.1007/s00066-01901555-1

46. Pignol JP, Olivotto I, Rakovitch E, et al. A multicenter randomized trial of breast intensity-modulated radiation therapy to reduce acute radiation dermatitis. J Clin Oncol. 2008;26 (13):2085-2092. doi:10.1200/JCO.2007.15.2488 
47. Mukesh MB, Barnett GC, Wilkinson JS, et al. Randomized controlled trial of intensity-modulated radiotherapy for early breast cancer: 5 -year results confirm superior overall cosmesis. J Clin Oncol. 2013;31(36):4488-4495. doi:10.1200/JCO.2013.49. 7842

48. Zhao H, He M, Cheng G, et al. A comparative dosimetric study of left sided breast cancer after breast-conserving surgery treated with VMAT and IMRT. Radiat Oncol. 2015;10:231. doi:10.1186/ s13014-015-0531-4

49. Haciislamoglu E, Colak F, Canyilmaz E, et al Dosimetric comparison of left-sided whole-breast irradiation with 3DCRT, forward-planned IMRT, inverse-planned IMRT, helical tomotherapy, and volumetric arc therapy. Phys Med. 2015;31(4): 360-367. doi:10.1016/j.ejmp.2015.02.005

50. Jin $G H$, Chen LX, Deng XW, Liu XW, Huang $Y$, Huang XB. A comparative dosimetric study for treating left-sided breast cancer for small breast size using five different radiotherapy techniques: conventional tangential field, filed-in-filed tangential-IMRT, multi-beam IMRT and VMAT. Radiat Oncol. 2013;8:89. doi:10.1186/1748-717X-8-89

51. Duane FK, McGale P, Teoh S, et al. International variation in criteria for internal mammary chain radiotherapy. Clin Oncol (R Coll Radiol). 2019;31(7): 453-461. doi:10.1016/j.clon.2019.04.007

52. Taylor CW, Wang Z, Macaulay E, Jagsi $R$, Duane F, Darby SC. Exposure of the heart in breast cancer radiation therapy: a systematic review of heart doses published during 2003 to 2013. Int J Radiat Oncol Biol Phys. 2015;93(4):845-853. doi:10. 1016/j.jijrobp.2015.07.2292

53. Murray Brunt A, Haviland JS, Wheatley DA, et al; FAST-Forward Trial Management Group. Hypofractionated breast radiotherapy for 1 week versus 3 weeks (FAST-Forward): 5 -year efficacy and late normal tissue effects results from a multicentre, non-inferiority, randomised, phase 3 trial. Lancet. 2020;395(10237):1613-1626. doi:10 1016/S0140-6736(20)30932-6

54. Poortmans PMP, Takanen S, Marta GN Meattini I, Kaidar-Person O. Winter is over: the use of artificial intelligence to individualise radiation therapy for breast cancer. Breast. 2020;49:194-200. doi:10.1016/j.breast.2019.11.011

55. Aznar MC, Duane FK, Darby SC, Wang Z, Taylor CW. Exposure of the lungs in breast cancer radiotherapy: a systematic review of lung doses published 2010-2015. Radiother Oncol. 2018;126(1): 148-154. doi:10.1016/j.radonc.2017.11.022

56. Nissen HD, Appelt AL. Improved heart, lung and target dose with deep inspiration breath hold in a large clinical series of breast cancer patients.
Radiother Oncol. 2013;106(1):28-32. doi:10.1016 j.radonc.2012.10.016

57. Lakosi F, Gulyban A, Simoni SB, et al. The influence of treatment position (prone vs. supine) on clip displacement, seroma, tumor bed and partial breast target volumes: comparative study. Pathol Oncol Res. 2016;22(3):493-500. doi:10.1007/s12253-015-0028-3

58. Rodgers $B$, Jaroszewski DE, Ashman JB, Rule WG, Sio TT, Keole SR. Advantages of post-mastectomy proton beam therapy in a breast cancer patient with pectus excavatum. J Med Cases. 2017;8(3):98-101. doi:10.14740/jmc2781w

59. DeCesaris CM, Rice SR, Bentzen SM, Jatczak J, Mishra MV, Nichols EM. Quantification of acute skin toxicities in patients with breast cancer undergoing adjuvant proton versus photon radiation therapy: a single institutional experience. Int J Radiat Oncol Biol Phys. 2019;104(5):1084-1090. doi:10.1016/ j.ijrobp.2019.04.015

60. Galland-Girodet S, Pashtan I, MacDonald SM, et al. Long-term cosmetic outcomes and toxicities of proton beam therapy compared with photon-based 3-dimensional conformal accelerated partial-breast irradiation: a phase 1 trial. Int J Radiat Oncol Biol Phys. 2014:90(3):493-500. doi:10. 1016/j.jijrobp.2014.04.008

61. Appelt AL, Vogelius IR, Bentzen SM. Modern hypofractionation schedules for tangential whole breast irradiation decrease the fraction size-corrected dose to the heart. Clin Oncol (R Coll Radiol). 2013;25 (3):147-152. doi:10.1016/j.clon.2012.07.012

62. Haviland JS, Owen JR, Dewar JA, et al; START Trialists' Group. The UK Standardisation of Breast Radiotherapy (START) trials of radiotherapy hypofractionation for treatment of early breast cancer: 10-year follow-up results of two randomised controlled trials. Lancet Oncol. 2013;14 (11):1086-1094. doi:10.1016/S1470-2045(13)70386-3

63. Whelan TJ, Pignol JP, Levine MN, et al. Long-term results of hypofractionated radiation therapy for breast cancer. N Engl J Med. 2010;362 (6):513-520. doi:10.1056/NEJMoa0906260

64. Poortmans $P$, Kaidar-Person O, Span P. Radiation oncology enters the era of individualised medicine. Lancet Oncol. 2017;18(2):159-160. doi:10. 1016/S1470-2045(16)30660-X

65. Hughes KS, Schnaper LA, Bellon JR, et al. Lumpectomy plus tamoxifen with or without irradiation in women age 70 years or older with early breast cancer: long-term follow-up of CALGB 9343. J Clin Oncol. 2013:31(19):2382-2387. doi:10. 1200/JCO.2012.45.2615

66. Whelan T, Levine M, Sussman J.

Hypofractionated breast irradiation: what's next?
J Clin Oncol. 2020;38(28):3245-3247. doi:10.1200/ JCO.20.01243

67. Vicini FA, Cecchini RS, White JR, et al. ong-term primary results of accelerated partial breast irradiation after breast-conserving surgery for early-stage breast cancer: a randomised, phase 3, equivalence trial. Lancet. 2019;394(10215) 2155-2164. doi:10.1016/S0140-6736(19)32514-0

68. Strnad V, Ott OJ, Hildebrandt G, et al; Groupe Européen de Curiethérapie of European Society for Radiotherapy and Oncology (GEC-ESTRO). 5-year results of accelerated partial breast irradiation using sole interstitial multicatheter brachytherapy versus whole-breast irradiation with boost after breast-conserving surgery for low-risk invasive and in-situ carcinoma of the female breast: a randomised, phase 3, non-inferiority trial. Lancet. 2016;387(10015):229-238. doi:10.1016/S0140-6736 (15)00471-7

69. Coles CE, Griffin CL, Kirby AM, et al; IMPORT Trialists. Partial-breast radiotherapy after breast conservation surgery for patients with early breast cancer (UK IMPORT LOW trial): 5-year results from a multicentre, randomised, controlled, phase 3 , non-inferiority trial. Lancet. 2017;390(10099): 1048-1060. doi:10.1016/S0140-6736(17)31145-5

70. Meattini I, Marrazzo L, Saieva C, et al. Accelerated partial-breast irradiation compared with whole-breast irradiation for early breast cancer: long-term results of the randomized phase III APBI-IMRT-Florence Trial. J Clin Oncol. 2020;38 (35):4175-4183. doi:10.1200/JCO.20.00650

71. Kaidar-Person O, Meattini I, Zippel D, Poortmans P. Apples and oranges: comparing partial breast irradiation techniques. Rep Pract Oncol Radiother. 2020;25(5):780-782. doi:10.1016 j.rpor.2020.07.008

72. Zhang $\mathrm{K}$, He X, Zhou Y, et al. Atorvastatin ameliorates radiation-induced cardiac fibrosis in rats. Radiat Res. 2015;184(6):611-620. doi:10.1667/ RR14075.1

73. van der Veen SJ, Ghobadi G, de Boer RA, et al. ACE inhibition attenuates radiation-induced cardiopulmonary damage. Radiother Oncol. 2015; 114(1):96-103. doi:10.1016/j.radonc.2014.11.017

74. Yu JM, Hsieh MC, Qin L, Zhang J, Wu SY. Metformin reduces radiation-induced cardiac toxicity risk in patients having breast cancer. Am J Cancer Res. 2019:9(5):1017-1026.

75. Du S, Zhou L, Alexander GS, et al. PD-1 modulates radiation-induced cardiac toxicity through cytotoxic T lymphocytes. J Thorac Oncol. 2018;13(4):510-520. doi:10.1016/j.jtho.2017.12.002 